\title{
Benefit segmentation of the container shipping market in Turkey
}

\author{
Gökcay Balci* \\ Huddersfield Business School, \\ Department of Logistics, Marketing, Hospitality and Analytics \\ University of Huddersfield \\ United Kingdom \\ Phone: + 44 (0) 1484473132 \\ E-mail: g.balci@hud.ac.uk \\ Ismail Bilge Cetin \\ Dokuz Eylul University \\ Tinaztepe Campus, 35160, Buca Izmir, Turkey
}

\section{To cite and reach final version of this article:}

Gökcay Balci \& Ismail Bilge Cetin (2020): Benefit segmentation of the container shipping market in Turkey, Maritime Policy \& Management, DOI: 10.1080/03088839.2020.1729436

Marketing policies have gained more importance in container shipping as the industry experiences challenges arising from commoditization. Market segmentation is fundamental to marketing policies, yet it needs a detailed analysis in container shipping. Accordingly, this paper aims to explore homogenous customer groups in container shipping by conducting a segmentation analysis, which can help container lines apply more efficient marketing policies. A survey study is conducted on 356 shippers in Turkey. The study develops five reliable and valid selection criteria factors and applies cluster analysis based on the selection criteria factors. The cluster analysis produces a total of six benefit segments which are differentiable. The segments are significantly identified by the demographic characteristics of shippers. The paper suggests several implications for the marketing policies of container lines.

Keywords: Segmentation; B2B marketing; container shipping; benefit segments; factor analysis; cluster analysis.

\section{Introduction}

Container lines need to comprehend what their customers need and want to deliver superior services to increase the perceived value of shippers (Vural, Göçer, and Halldórsson 2018). However, customer priorities are heterogeneous in container shipping services (Maloni, Gligor, and Lagoudis 2016). That is, although goods are carried in standardized containers, the market is heterogeneous in terms of customer variety. Shippers differ from each other through dissimilarities in their cargo characteristics, geographical traits of their hinterlands, shipment volumes, and their company policies (Balci and Cetin 2017). This heterogeneity keeps increasing as more cargoes are transported in containers due to the containerization of bulk and general cargoes (Rodrigue and Notteboom 2015). The heterogeneity of the market can also be witnessed from selection criteria studies in container shipping, in which criteria ranking of respondents diverges (Balci, Cetin, and Tanyeri 2018). 
Container lines should perceive these heterogeneous expectations and deliver customized offerings to adopt more effective marketing policies. However, understanding the priority of each customer would also be inefficient as the cost of the process would exceed the benefits received from it. Market segmentation can be an ideal solution to understand the specific needs and wants of different customer groups and implement differentiated marketing programs efficiently in B2B markets (Brotspies and Weinstein 2019). Segmentation - a fundamental marketing strategy - can enable container lines to identify heterogeneous customer groups. Market segmentation has several advantages for container lines, such as allocating marketing resources more efficiently, implementing differentiated marketing, targeting specific groups, and arranging customized promotional strategies (Kotler and Armstrong 2011). Segmentation can also help companies customize their marketing communication, which is crucial for personal interaction and relations in commodity-like B2B markets (Ulaga and Eggert 2006).

Several researchers have investigated market segmentation in the container shipping domain. Collison (1984) applied segmentation analysis to shippers in the Pacific Northwest - Central Alaska route, based on readily available demographic characteristics. Lu, Lai and Cheng (2005) applied segmentation on shippers in Taiwan in terms of container lines' website service attributes. Wen and Lin (2016) implemented segmentation on freight forwarders operating on the Taiwan - South China route. From their qualitative study, Balci and Cetin (2017) proposed a segmentation framework that includes possible segmentation descriptors. Finally, Chen, Chiu, and Chang (2017) segmented container shippers to determine service attributes affecting customer retention.

Although the container shipping literature has well-written segmentation studies, none of them aims to investigate benefit segmentation which finds out post-hoc segments based on selection criteria or purchase approaches of customers (Paker and Vural 2016). Lu, Lai, and Cheng (2005) reveals the benefit segments of container shippers but based on the website services. Wen and Lin (2016) apply benefit segmentation to freight forwarders. Although Chen, Chiu, and Chang (2017) implement segmentation, their purpose is not to reveal benefit segments but instead to determine service attributes affecting customer retention in different groups.

Besides, the literature suggests that B2B segmentation is a dynamic and ongoing process that should be periodically reviewed (Mitchell and Wilson 1998). Container shipping is also a dynamic market in which the carriers, market structure, and selection criteria priority have changed (Balci and Cetin 2017). The concentration has intensified significantly in the market due to the mergers and acquisitions in recent years. According to Alphaliner, the top four container lines generate over $50 \%$ of the total TEU capacity. However, the competition has become even keener in recent years and the price sensitivity of shippers has increased as the services of container lines have become alike (Balci, Cetin, and Tanyeri 2018; Maloni, Gligor, and Lagoudis 2016). This situation has increased the importance of marketing research in the container shipping market as a recent Transport Policy special issue also suggests (Parola, Pallis, and Song 2019). Understanding shipper needs and wants and revealing their 
heterogeneous expectations is relevant in the current market environment. Thus, there exists a need to explore the benefit segments of container shippers.

Accordingly, the main purpose of this paper is to apply benefit segmentation to shippers in the container shipping market by considering their selection criteria. An important issue with benefit segmentation is to identify segments with readily available demographic characteristics (Brotspies and Weinstein 2019). Identifiable segments are measurable, actionable, and accessible, which are important criteria for effective segmentation (Kotler and Armstrong 2011). Hence, this paper also aims to identify those shipper demographics that can help describe the benefit segments. The paper first explains the methodology, which includes exploratory and confirmatory factor analyses, cluster analysis, and post-hoc tests in contingency tables. The benefit segments explored in the research are then described in detail. Finally, the discussion and conclusions offer several implications for the literature and container shipping companies.

\section{Methodology}

The purpose of this study is to explore and identify the benefit segments of container shippers. We conducted survey research with exporters located in the Aegean Region of Turkey. As shown in Figure 1, the study first developed selection criteria measure and explored the underlying factors by applying exploratory and confirmatory factor analyses (EFA and CFA). Then, cluster analysis based on factor scores was employed to ascertain the different customer groups. Finally, the research created contingency tables between the segment memberships of shippers and several demographic characteristics of shippers to determine the significant associations. The effectiveness and reliability of this procedure are well documented in the literature of market segmentation, in both industrial contexts (Raman and Menon 2018) and consumer contexts (Grise and El-Geneidy 2018).

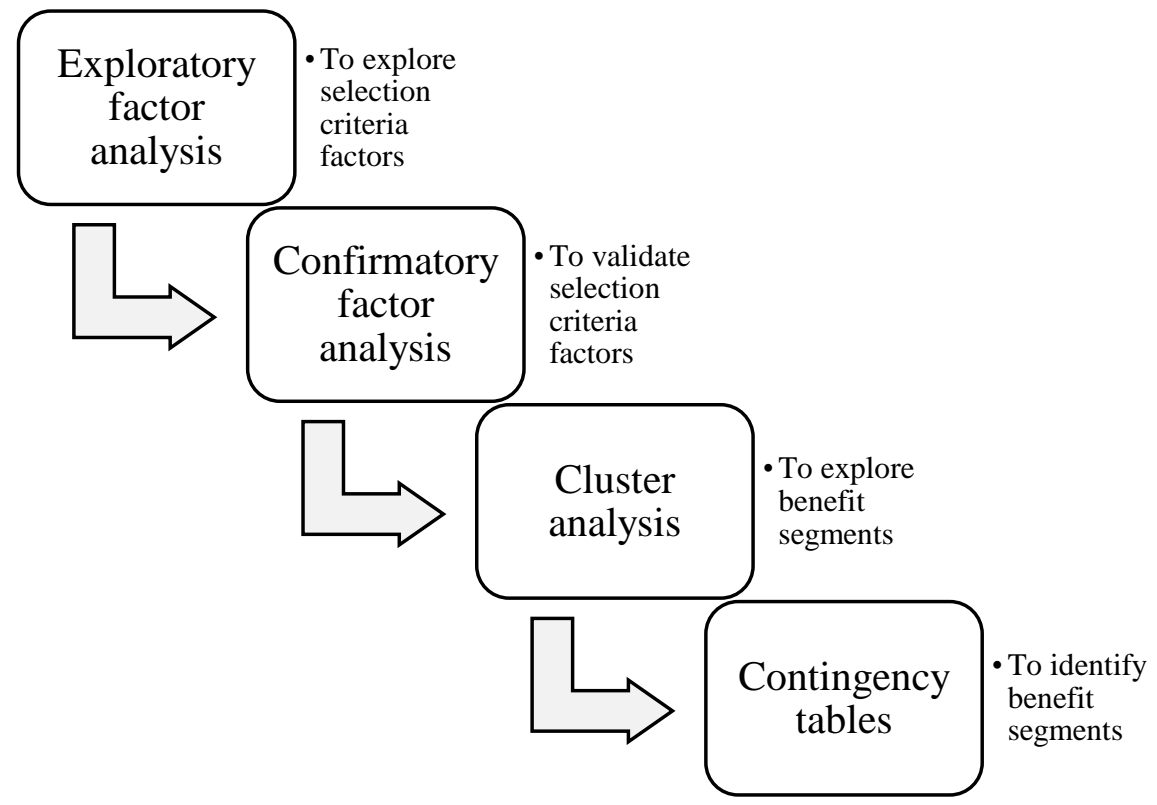

Figure 1 Segmentation analysis process

\subsection{Questionnaire development and sampling}


The questionnaire variables were created based on the container shipping literature and 15 semi-structured interviews averaging 45 minutes with experts in the Aegean Region (See Table 1). Three of these lectured at a university, five worked in container carrier companies, three worked in freight forwarding, and four worked in shipper companies. Our questionnaire form was finalized based on their opinions regarding the selection criteria variables and the category levels of the nominal questions.

In the questionnaire, following the suggestions of interviewees, shippers are asked to reply the questions by considering their most-exported cargo because some shippers export more than a single product type, and responses might vary according to the product type. The questionnaire consisted of three sections. The first section included product and companyrelated questions. The categorical questions included industry of cargo, cargo value per container, most frequent destination, seaway usage frequency, monthly container volume, number of employees, and most preferred delivery terms. We included one open-ended question to ask shippers to describe their products in detail, which allowed us to determine the Industrial Benchmark Category (IBC). Three categories are used in the IBC: Basic Materials, industrials, and consumer goods. We have also asked two metric descriptors: the perceived sensitiveness of shippers' cargo and the perceived competition level of shippers' industry. The sensitiveness of cargo is asked with three dimensions: Sensitiveness to dirtiness, sensitiveness to smell, and sensitiveness to moisture. The five-point questions are anchored as 1=not sensitive and 5=very sensitive. The competition level is asked with three statements (see Table 2) with five-point Likert questions anchored as $1=$ totally disagree and $5=$ totally agree. Cronbach's alpha level of cargo sensitiveness and competition level exceed 0.7 (former is 0.94 and the latter is 0.75 )

The second section included 25 selection criteria. After creating the list of most frequent variables, we collected the opinions of the interviewees. The respondents were asked to weigh the importance level they attached to each criterion ( $1=$ very low importance, $7=$ very high importance). The last section of the questionnaire asked for the position and experience of the respondents.

Regarding sampling, we focused on exporters located in the Aegean Region, which has been a traditional export hub in Turkey. In this region, there are four container terminals, all located in Izmir city, for exporters to ship their cargoes. The membership list of the Aegean Exporters' Union was chosen as the population of the study. This list had 3,951 usable contact details for shippers, including address, city, phone number, website, and company e-mail addresses. The data was collected by a self-completion online questionnaire in December 2018. Companies were kindly asked to ignore the questionnaire if they did not use sea transportation for their exports. A total of 356 valid responses were received.

Table 1 Selection Criteria Variables

\begin{tabular}{llll}
\hline Variable & Abbreviation & Source \\
\hline 1. $\begin{array}{l}\text { Short transit time } \\
\text { Transit }\end{array}$ & $\begin{array}{l}\text { (Balci, Cetin, and Tanyeri 2018; Collison 1984; } \\
\text { Durvasula, Lysonski, and Mehta 2000; Lu 2003; } \\
\text { Wong, Yan, and Bamford 2008) } \\
\text { 2. Directness of sailing }\end{array}$ & $\begin{array}{l}\text { Directness } \\
\text { (Kannan, Bose, and Kannan 2011) }\end{array}$ \\
$\begin{array}{l}\text { Damage-free } \\
\text { transportation* }\end{array}$ & Damage-free & $\begin{array}{l}\text { (Balci, Cetin, and Tanyeri 2018; Collison 1984; } \\
\text { Lu, 2003) }\end{array}$ \\
4. Low freight rates & Freight & (Durvasula, Lysonski, and Mehta 2000; Wong, \\
\hline
\end{tabular}




\begin{tabular}{|c|c|c|}
\hline & & Yan, and Bamford 2011) \\
\hline Flexibility in payment & Flexinpayment & (Kannan, Bose, and Kannan 2011) \\
\hline $\begin{array}{l}\text { 6. Willing to negotiate } \\
\text { freight rate }\end{array}$ & Negotiation & $\begin{array}{l}\text { (Collison 1984; Lu 2003; Wong, Yan, and } \\
\text { Bamford 2008) }\end{array}$ \\
\hline $\begin{array}{l}\text { 7. Low local port fees of } \\
\text { carrier }\end{array}$ & Localcost & Interviews \\
\hline 8. Fast documentation & Fastdoc & $\begin{array}{l}\text { (Durvasula, Lysonski, and Mehta 2000; } \\
\text { Kannan, Bose, and Kannan 2011) }\end{array}$ \\
\hline $\begin{array}{l}\text { 9. Error-free } \\
\text { documentation }\end{array}$ & Errorfreedoc & (Lu 2003) \\
\hline $\begin{array}{l}\text { 10. Quick response to } \\
\text { inquiries }\end{array}$ & Quickresponse & (Lu 2003; Wong, Yan, and Bamford 2008) \\
\hline $\begin{array}{l}\text { 11. Effectiveness of online } \\
\text { tracking }\end{array}$ & Tracking & (Kannan, Bose, and Kannan 2011; Lu 2003) \\
\hline $\begin{array}{l}\text { 12. Availability of empty } \\
\text { containers* }\end{array}$ & Emptycont & (Kannan, Bose, and Kannan 2011) \\
\hline $\begin{array}{l}\text { 13. Sailing on promised } \\
\text { time }\end{array}$ & Ontimesailing & $\begin{array}{l}\text { (Kannan, Bose, and Kannan 2011; Lu 2003; } \\
\text { Wong, Yan, and Bamford 2008) }\end{array}$ \\
\hline $\begin{array}{l}\text { 14. Accessibility of line } \\
\text { personnel }\end{array}$ & Accessibility & (Balci, Cetin, and Tanyeri 2018) \\
\hline $\begin{array}{l}\text { 15. Wide global network of } \\
\text { carrier }\end{array}$ & Network & (Durvasula, Lysonski, and Mehta 2000) \\
\hline $\begin{array}{l}\text { 16. Ability of carrier to offer } \\
\text { effective door-to-door } \\
\text { shipment }\end{array}$ & $\mathrm{D} 2 \mathrm{D}$ & $\begin{array}{l}\text { (Collison 1984; Lu 2003; Wong, Yan, and } \\
\text { Bamford 2008) }\end{array}$ \\
\hline $\begin{array}{l}\text { 17. Availability of } \\
\text { warehouse service }\end{array}$ & Warehouse & (Collison 1984; Lu 2003) \\
\hline $\begin{array}{l}\text { 18. Availability of } \\
\text { compatible EDI }\end{array}$ & EDI & (Lu 2003) \\
\hline $\begin{array}{l}\text { 19. Customized } \\
\text { performance reporting }\end{array}$ & Reporting & Interviews \\
\hline $\begin{array}{l}\text { 20. Frequency of visiting by } \\
\text { carrier personnel }\end{array}$ & Visiting & (Balci, Cetin, and Tanyeri 2018; Lu 2003) \\
\hline $\begin{array}{l}\text { 21. Strong personal relation } \\
\text { with carrier personnel }\end{array}$ & Relations & $\begin{array}{l}\text { (Balci, Cetin, and Tanyeri 2018; Durvasula, } \\
\text { Lysonski, and Mehta 2000) }\end{array}$ \\
\hline $\begin{array}{l}\text { 22. Consultancy given by } \\
\text { carrier when necessary }\end{array}$ & Consultancy & (Balci, Cetin, and Tanyeri 2018) \\
\hline $\begin{array}{l}\text { 23. Long demurrage free- } \\
\text { time period* }\end{array}$ & Freetime & (Kannan, Bose, and Kannan 2011) \\
\hline $\begin{array}{l}\text { 24. Cleanliness of } \\
\text { containers* }\end{array}$ & Clean & $\begin{array}{l}\text { (Balci, Cetin, and Tanyeri 2018; Collison 1984; } \\
\text { Kannan, Bose, and Kannan 2011; Lu 2003) }\end{array}$ \\
\hline $\begin{array}{l}\text { 25. Reputation of the } \\
\text { carrier in market* }\end{array}$ & Reputation & $\begin{array}{l}\text { (Durvasula, Lysonski, and Mehta 2000, Kannan, } \\
\text { Bose, and Kannan 2011) }\end{array}$ \\
\hline
\end{tabular}

*These variables were deleted during the measurement development process.

Table 2 Items of perceived competition level of shippers

\begin{tabular}{lll}
\hline Variable & Abbreviation & Adapted from \\
\hline Competition in our industry is cut-throat & Competition1 & (Fynes, de Búrca, and Voss \\
& & $\begin{array}{l}\text { 2005) } \\
\text { (Salavou, Baltas, and Lioukas }\end{array}$ \\
The number of competitors is high in our & Competition2 & $\begin{array}{l}\text { 2004) } \\
\text { industry }\end{array}$ \\
Competitors in this market pursue & Competition3 & (Fynes, de Búrca, and Voss \\
\hline
\end{tabular}




\subsection{Identification and Validation of Selection Criteria Factors}

Exploratory factor analysis (EFA) and confirmatory factor analysis (CFA) were used to identify and validate the underlying factors of the selection criteria. Our sample size was adequate for conducting both analyzes as the suggested minimum number of observations is 5 , or 10 times the number of variables (Hair et al. 2014). We also checked the Kaiser-MeyerOlkin (KMO) sampling adequacy test result, which should have a score between 0.5 and 1 . The KMO score was 0.856. For EFA, we applied principal component analysis with eigenvalues greater than 1 to extract the factors and chose Varimax rotation. We deleted variables based on two conditions: when a variable had high cross-loadings and when the factor loading of a variable was too low for any of the factors (Hair et al. 2014). Accordingly, "damage-free transportation performance" was eliminated because of the low factor loading (0.368) while "the reputation of carrier in the market" and "availability of empty containers" were deleted because of high cross-loadings.

CFA was conducted using SPSS AMOS version 22 to ensure the reliability and validity of the factors derived from EFA, and to check the model fit. According to Hair et al. (2014), the standardized factor loadings should exceed 0.5. Hence, "demurrage freetime" and "cleanliness of containers" were removed from the measure before running EFA and CFA again. In the final version of the measure, EFA detected no cross-loadings and all standardized factor loadings were above 0.5 in CFA. As a result, we attained a five-factor solution consisting of 20 observed variables. The five factors explained $70.6 \%$ of the total variance.

The reliability of the factors was measured in two ways: Cronbach's Alpha value and composite reliability. Cronbach's Alpha and composite reliability (CR) scores are considered adequate between 0.6-0.7, and better if they exceed 0.7 (Bagozzi and Yi 1988). The Alpha and composite reliability values of all constructs well exceeded 0.7 in this study. Convergent validity is defined by Malhotra and Birks $(2007,359)$ as "the extent to which the scale correlates positively with other measurements of the same" while discriminant validity is defined as "the extent to which a measure does not correlate with other constructs from which it is supposed to differ". The convergent validity of each construct was measured by average variance extracted (AVE), while discriminant validity was measured by checking maximum shared variance (MSV). AVE should be higher than 0.5 while MSV should be less than AVE (Hair et al. 2014; Tarhini, Teo, and Tarhini 2016). All the latent factors in this study met the minimum requirements, as shown in Table 3.

Table 3 Reliability and Validity Scores of Selection Criteria Factors

\begin{tabular}{llllll}
\hline Factor & \% of variance & Alpha & CR & AVE & MSV \\
\hline Value added services (VAS) & $19.5 \%$ & 0.88 & 0.88 & 0.56 & 0.29 \\
Responsiveness & $15.8 \%$ & 0.82 & 0.83 & 0.51 & 0.25 \\
Cost & $15.7 \%$ & 0.90 & 0.90 & 0.70 & 0.25 \\
\hline
\end{tabular}




\begin{tabular}{llllll}
\hline Time & $10.0 \%$ & 0.81 & 0.85 & 0.76 & 0.11 \\
Relational & $9.6 \%$ & 0.72 & 0.78 & 0.54 & 0.29 \\
\hline
\end{tabular}

Fit Indices: $\mathrm{CMIN} / \mathrm{DF}=3.00(462.0 / 154), \mathrm{CFI}=0.92, \mathrm{TLI}=0.90, \mathrm{RMSEA}=0.075, \mathrm{SRMR}=0.071$

In addition to the reliability and validity of the constructs, goodness of fit indices of CFA model were evaluated. One of the basic absolute fit indices is CMIN/DF (Chi-square). If this is lower than 5.00, then the model is considered to have a good fit (Kline 2016). CMIN/DF was 3.00 in our model. However, since the CMIN/DF score is very sensitive to sample size, other indices were also checked. One is the Root Mean Square Error of Approximation (RMSEA). Hair et al. (2014) suggest a cutoff value of RMSEA between 0.03 and 0.08 . Our RMSEA score of 0.075 fell within this range.

According to Brown (2015), the Tucker Lewis Index (TLI) and Comparative Fit Index (CFI) are commonly recognized as comparative indices. TLI and CFI scores range between 0 and 1 , and it is better if the score is closer to 1. Hair et al. (2014) suggest that scores above 0.90 demonstrate a good model fit. Our TLI and CFI scores were 0.90 and 0.92 respectively. The Standardized Root Mean Residual (SRMR) score (0.071) of the results also indicated that the model fits as this was lower than the cutoff value of 0.08 (Hu and Bentler 1999).

\subsection{Cluster analysis}

Cluster analysis was applied to explore the segments of container shippers based on their container line selection criteria factors. The main purpose of cluster analysis is to classify observations or objects in an optimal way so that members in a group are similar while groups are dissimilar (Rencher 2002). Cluster analysis is a multi-step process so a researcher should make decisions regarding several considerations. This study adopted the clustering process of Hair et al. (2014, 426-438). Regarding the clustering variables, we used the regression scores of the five selection criteria factors. Factor scores are defined as "composite scores estimated for each respondent on the derived factors" (Malhotra and Birks 2007, 648). Factor scores are standardized values, which have a mean value of 0 and a standard deviation of 1 . We applied case-by standardization to reduce any potential response-style effects (Hair et al. 2014).

Regarding the clustering algorithm, hierarchical clustering was applied with an agglomerative approach whereby an object is merged to the most similar object in each step until the entire population is represented through a single cluster. In other words, each object is a cluster at the beginning and the number of clusters decreases at each step until all the clusters are combined under a single cluster (Rencher 2002). Ward's method, which is designed to minimize the variance within a cluster, is one of the most preferred clustering methods in marketing research (Malhotra and Birks, 2007). In this method, the similarity is measured by the "sum of squares within the clusters summed over all variables", rather than calculating similarity as a single distance (Hair et al. 2014, 442). Ward's method has the advantage of producing clusters with equal or similar sizes (Sarstedt and Mooi 2014). Thus, many B2B segmentation studies have also used Ward's method as their clustering algorithm (Jadczakova 
2013; Shahrabi, Najafabadi, and Sahebnasagh 2009). Squared Euclidian was selected as the distance measure. The analysis was performed on SPSS version 21.

An important issue when applying cluster analysis is the choice of the number of segments. Because cluster analysis is a non-inferential and exploratory technique, the ideal number of clusters in the solution is mostly based on the theory and the researcher's judgment (Malhotra and Birks 2007). Nevertheless, there are some general recommendations and guidance that can help researchers decide on the number of clusters (Ketchen and Shook 1996, 446). One of the most common methods is analyzing the coefficients in the agglomeration schedule produced in SPSS (Hair et al. 2014), which makes it possible to identify the stopping point for determining the number of clusters. Specifically, when a major increase occurs in the coefficients, this is a potential signal for stopping the agglomeration of clusters (Ketchen and Shook 1996). Following this procedure, we decided on a six-cluster solution as optimal.

\section{Results}

\subsection{Descriptive results}

According to our results, approximately $19 \%$ of respondents were either general manager, CEO, or company owner, with $34 \%$ being export, foreign trade, or logistics managers. Around 35\% were export or logistics specialists, while $10 \%$ were responsible for purchasing. The experience level of the respondents was quite satisfactory in that only less than $15 \%$ had between 1-3 years of experience in their positions, whereas almost $50 \%$ had more than 10 years' experience.

As shown in Table 4, the most frequent industry category that the respondents' companies belonged was dry food, with almost $20 \%$. This is quite similar to the population as the Aegean Region has traditionally been an export area for food exporters. It was followed by mineral exporters, tiles and ceramic producers, spare part exporters, and chemicals and plastics producers. The least common categories were fashion and textile companies, with each around $5 \%$.

Table 4 Industry Classification of Respondent Companies

\begin{tabular}{lcr}
\hline $\begin{array}{l}\text { Industry of } \\
\text { companies }\end{array}$ & Frequency & Percent \\
\hline Dry food & 71 & $19.9 \%$ \\
\hline Minerals & 48 & $13.5 \%$ \\
\hline Tiles \& ceramics & 39 & $11.0 \%$ \\
\hline Machine & 37 & $10.4 \%$ \\
\hline Spare part & 35 & $9.8 \%$ \\
\hline Chemicals \& plastics & 34 & $9.6 \%$ \\
\hline Refrigerated food & 30 & $8.4 \%$ \\
\hline
\end{tabular}




\begin{tabular}{lrr}
\hline Fashion & 18 & $5.1 \%$ \\
\hline Textile & 16 & $4.5 \%$ \\
\hline Others & 28 & $7.9 \%$ \\
\hline Total & 356 & $100.0 \%$ \\
\hline
\end{tabular}

Considering the IBC classification of the respondent companies' products, around $25 \%$ were basic materials, 33\% were industrial goods, and $41 \%$ were consumer products (See Table 5). Approximately $25 \%$ of the products had low cargo value per container (0-14,999USD) while $55 \%$ had medium value (15,000-44,999USD), and over $20 \%$ had high value $(45,000 \mathrm{USD}$ and more).

Table 5 IBC Classification of products and cargo value per container

\begin{tabular}{llllll}
\hline \multicolumn{3}{c}{ IBC Category of products } & \multicolumn{3}{c}{ Cargo value per container } \\
\hline IBC Category & Frequency & Percent & Cargo value & Frequency & Percent \\
\hline Basic Materials & 91 & $25.6 \%$ & Low & 86 & $24.2 \%$ \\
Industrials & 118 & $33.1 \%$ & Medium & 196 & $55.1 \%$ \\
Consumer & 147 & $41.3 \%$ & High & 74 & $20.8 \%$ \\
Total & 356 & $100 \%$ & Total & 356 & $100 \%$ \\
\hline
\end{tabular}

Considering the monthly container volume, the largest proportion of companies (38\%) exported 1-5 containers per month, followed by 6-14 containers per month (28\%). The smallest groups were '40-99 containers' and ' 100 and more containers' categories $(8.7 \%$ and $8.1 \%$ respectively). Almost 17\% of surveyed companies shipped between '15-39 containers' per month. Regarding the number of employees, almost $40 \%$ of the companies had ' $50-249$ employees' while around $16 \%$ had 1-9 or 250 and more employees.

Regarding the most preferred delivery terms of shippers, $50 \%$ of respondents stated that their most preferred delivery term was FOB\&FAS while around 28\% preferred CFR\&CIF, and $21 \%$ preferred DAP\&DDP. How often a company prefers sea transportation is also an important issue. $46 \%$ of respondents indicated that their company only uses seaway transportation while 38\% mostly use seaway transport. On the other hand, around 15\% rarely use seaway transportation. Considering the destination region of their company's export cargo, the most frequent was Northern Europe (25\%), followed by the Middle East and North America, with $16 \%$ each. The Far East \& Asia was the fourth most frequent destination.

\subsection{Segmentation analysis results}

The cluster analysis based on the selection criteria factors produced a total of six segments ( mean number of members $=59$; median $=66$; range $=31-75$ ). Table 6 presents the number of members and the mean value of each segment's factor score. A one-way ANOVA was conducted to assess if the factor scores differed significantly across segments. The results 
indicated that all factors were significantly different across the segments at 0.000 significance level.

Table 6 Mean factor scores and population of the segments

\begin{tabular}{|c|c|c|c|c|c|c|}
\hline & \multicolumn{6}{|c|}{ Segments } \\
\hline & 1 & 2 & 3 & 4 & 5 & 6 \\
\hline & Mean & Mean & Mean & Mean & Mean & Mean \\
\hline Value-added Services & -.68494 & .57313 & -.77638 & 1.14750 & .31377 & -.66797 \\
\hline Responsiveness & .05234 & .34344 & -.06451 & -.76807 & .39400 & .35013 \\
\hline Cost & .72043 & .11735 & .64766 & .05133 & -1.48327 & -.57214 \\
\hline Time & .30153 & -.00719 & -.55829 & -.04600 & -.63748 & .67023 \\
\hline Relations & -.48454 & -1.34593 & .58469 & .40437 & .80146 & .16361 \\
\hline Number of members & 44 & 64 & 69 & 75 & 31 & 73 \\
\hline
\end{tabular}

To better interpret the segments, Figure 2 was created to illustrate the scores graphically. The figure shows how each segment differs from the others in terms of segmenting variables (factor scores). The height of the bars in each cluster does not indicate the most important or least important variable in that cluster. Instead, it shows how factor scores in each segment differ from the overall average. For instance, it does not mean that the fourth segment attaches more importance to VAS than responsiveness. Instead, it means that the VAS mean of this segment is much higher than the average VAS score across the segments. Similarly, the mean score of responsiveness in this segment is lower than the average responsiveness score across the segments. Each segment was named by considering their scores on the selection criteria factors. 


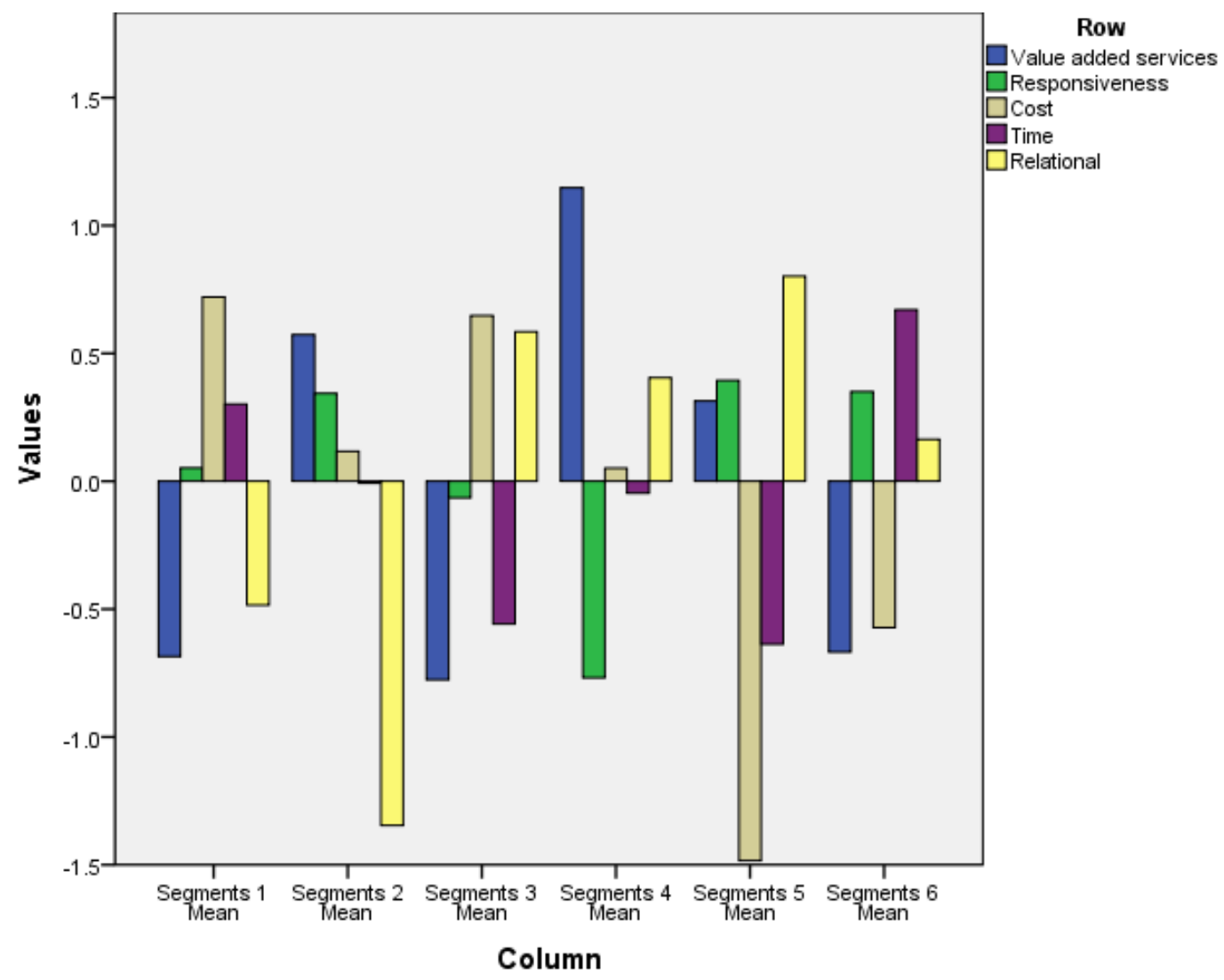

Figure 2 Bar chart display of factor scores across segments

Besides understanding the selection criteria expectations of each segment, it is also critical to identify these segments via readily available demographic characteristics. Contingency tables using Chi-square tests were used to identify the significant descriptors of the segments. Individual cells were investigated through post-hoc tests. As a post-hoc test, adjusted residuals, which are z-scores, were utilized to investigate each cell in the Chi-square analysis (MacDonald and Gardner 2000). Table 7, which summarizes all the contingency tables, shows the significant positive and negative associations between the descriptors and segment memberships.

Table 7 Significant associations between the segments and descriptors

\begin{tabular}{|c|c|c|c|c|c|c|}
\hline & $\begin{array}{c}\text { Time- } \\
\text { sensitive } \\
\text { cost seeker }\end{array}$ & $\begin{array}{c}\text { Pragmatic } \\
\text { service buyers }\end{array}$ & $\begin{array}{c}\text { Non-urgent } \\
\text { cost } \\
\text { seekers } \\
\end{array}$ & $\begin{array}{l}\text { Value- } \\
\text { added } \\
\text { service } \\
\text { buyers } \\
\end{array}$ & $\begin{array}{c}\text { Relationship } \\
\text { seekers }\end{array}$ & $\begin{array}{c}\text { Time } \\
\text { seekers }\end{array}$ \\
\hline Industry & $\begin{array}{l}\text { Chemicals } \\
\& \text { plastics }\end{array}$ & Machine $^{2}$ & $\begin{array}{l}\text { Minerals }{ }^{1} / \\
\text { Refrigerated } \\
\text { food }^{2}\end{array}$ & $\begin{array}{l}\text { Fashion }^{1} / \\
\text { Machine }^{2}\end{array}$ & Textile $^{1}$ & $\begin{array}{l}\text { Machine, } \\
\text { Refrigerated } \\
\text { food }^{1} / \\
\text { Minerals }^{2}\end{array}$ \\
\hline IBC & & & $\begin{array}{l}\text { Basic } \\
\text { Materials }^{1 /} \\
\text { Consumer }^{2}\end{array}$ & & & $\begin{array}{l}\text { Industrials }^{1} / \\
\text { Basic } \\
\text { materials }^{2}\end{array}$ \\
\hline
\end{tabular}




\begin{tabular}{|c|c|c|c|c|c|c|}
\hline Cargo Value & & & $\begin{array}{l}\text { Low value }{ }^{1} \\
/ \\
\text { High value }^{2}\end{array}$ & $\begin{array}{l}\text { High } \\
\text { value }^{1} / \\
\text { Low } \\
\text { value }^{2}\end{array}$ & $\begin{array}{l}\text { Medium } \\
\text { value }^{1}\end{array}$ & $\begin{array}{l}\text { Medium } \\
\text { value }^{1 /} \\
\text { Low value }^{2}\end{array}$ \\
\hline Destination & $\begin{array}{l}\text { Northern } \\
\text { Europe }^{1}\end{array}$ & $\begin{array}{l}\text { Eastern } \\
\text { Mediterranean }{ }^{1}\end{array}$ & $\begin{array}{l}\text { North } \\
\text { America }^{1} / \\
\text { Northern } \\
\text { Europe }^{2}\end{array}$ & $\begin{array}{l}\text { North } \\
\text { Africa and } \\
\text { Eastern } \\
\text { Med.2 }\end{array}$ & $\begin{array}{l}\text { Middle East }{ }^{1} / \\
\text { Northern } \\
\text { Europe }^{2}\end{array}$ & \\
\hline $\begin{array}{l}\text { Seaway } \\
\text { usage }\end{array}$ & Rarely $^{1}$ & & $\begin{array}{l}\text { All }{ }^{1} / \\
\text { Rarely }^{2}\end{array}$ & $\begin{array}{l}\text { Mostly }^{1} / \\
\text { Rarely }^{2}\end{array}$ & & $\begin{array}{l}\text { Rarely }{ }^{1} / \\
\text { All }^{2}\end{array}$ \\
\hline $\begin{array}{l}\text { Monthly } \\
\text { container }\end{array}$ & $\begin{array}{l}1-5^{1} / \\
100 \text { and } \\
\text { more }^{2}\end{array}$ & $40-99^{1} / 1-5^{2}$ & & $\begin{array}{l}100 \text { and } \\
\text { more }^{1} / \\
1-5^{2}\end{array}$ & & $\begin{array}{l}1-5^{1} / \\
100 \text { and } \\
\text { more }^{2}\end{array}$ \\
\hline $\begin{array}{l}\text { No of } \\
\text { Employee }\end{array}$ & & $10-49^{2}$ & $1-9^{1}$ & & 250 and more ${ }^{1}$ & $\begin{array}{l}250 \text { and } \\
\text { more }^{2}\end{array}$ \\
\hline $\begin{array}{l}\text { Delivery } \\
\text { terms }\end{array}$ & $\begin{array}{l}\text { FOB \& } \\
\text { FAS }^{1}\end{array}$ & $\begin{array}{r}\text { DAP \& DDP1 / } \\
\text { FAS \& FOB } 2\end{array}$ & $\begin{array}{l}\text { FOB \& } \\
\text { FAS } 1 / \\
D^{1} \text { \& \& } \\
\text { DDP }^{2}\end{array}$ & & & \\
\hline $\begin{array}{l}\text { Cargo } \\
\text { sensitive- } \\
\text { ness Rank }\end{array}$ & $\begin{array}{l}2^{\text {nd }} \\
(4.70)^{*}\end{array}$ & $\begin{array}{l}4^{\text {th }} \\
(4.06)\end{array}$ & $\begin{array}{l}6^{\text {th }} \\
(3.80)\end{array}$ & $\begin{array}{l}3^{r d} \\
(4.32)\end{array}$ & $\begin{array}{l}5^{\text {th }} \\
(4.02)\end{array}$ & $\begin{array}{l}1^{\text {st }} \\
(4.78)\end{array}$ \\
\hline $\begin{array}{l}\text { Competi- } \\
\text { tion level } \\
\text { Rank }\end{array}$ & $\begin{array}{l}5^{\text {th }} \\
(3.74)^{*}\end{array}$ & $\begin{array}{l}2^{\text {nd }} \\
(3.99)\end{array}$ & $\begin{array}{l}3^{\text {rd }} \\
(3.97)\end{array}$ & $\begin{array}{l}1^{s t} \\
(4.11)\end{array}$ & $\begin{array}{l}4^{\text {th }} \\
(3.85)\end{array}$ & $\begin{array}{l}6^{\text {th }} \\
(3.56)\end{array}$ \\
\hline
\end{tabular}

${ }^{1}$ Significant positive association at 0.05 level

${ }^{2}$ Significant negative association at 0.05 level

*Mean score of five-point scale

Segment 1 (Time-sensitive cost seekers)

Segment 1 had the highest mean value on the cost factor. Its mean value for the time was the second-highest among the segments while the responsiveness value was near average point. This segment had a substantially lower VAS value. It also had the second-lowest average relational factor value across the segments. The most prominent characteristic of this segment is its score on the cost factor. This segment is thus certainly more cost-sensitive than other segments, although this characteristic resembles Segment 3 as well. However, these two segments differ in terms of time and relations. Considering these issues, Segment 1 was named "time-sensitive cost seekers" (TCS).

The positive significant industry category of the TCS segment was chemicals \& plastics. IBC categories - basic materials, industrials, and consumers - were almost evenly distributed in this segment. The significant leading destination was Northern Europe while the prominent seaway usage category was rarely seaway, comprising $30 \%$ of the segment. Approximately 
$55 \%$ of shippers load 1-5 containers per month. The second-largest category in this segment was 6-14 containers. The smallest and negatively significant group in this segment was shippers loading 100 and more containers. The leading delivery term was FOB\&FAS. This segment is ranked 2 nd on cargo sensitiveness and 5th on competition level.

\section{Segment 2 (Pragmatic service buyers)}

Segment 2 stands out by having the lowest score on the relational factor. This indicates that members in this segment make more pragmatic decisions than the other segments, while personal relations are less important. In this segment, VAS, responsiveness, and cost factors scored higher than average, although the scores were not greatly higher than the average of all segments. In particular, the cost had a very close score to the average while time was at the average level. Considering the segment's extremely low score on relations and its relatively higher scores on VAS and responsiveness, the factor was named "pragmatic service buyers" (PSB).

One of the most distinguishing descriptors of PSB was its association with delivery terms, with $37.5 \%$ of this segment consisting of DAP\&DDP shippers with a very high adjusted residual score (3.5). This segment had a high negative association with the FOB\&FAS delivery term, which is consistent because DAP and FOB are direct opposites regarding the distribution of shipment responsibilities between exporter and importer. Another strong characteristic of this segment was its positive association with large volume shippers and negative association with small shippers. Moreover, customers that mostly ship to the Eastern Mediterranean were positively associated with this segment whereas machine shippers were negatively associated. This segment is ranked 4th on cargo sensitiveness and 2nd on competition level.

\section{Segment 3 (Non-urgent cost seekers)}

Segment 3 had the second-highest score on cost and relations across all segments whereas it had the lowest score on VAS, and the second-lowest score on time. While members in this segment attached particular importance to cost of service, their score on time was remarkably lower than the overall average - unlike the "time-sensitive cost seekers". Relations were also important for this segment, whereas VAS had almost no importance, like Segment 1 and Segment 6. Responsiveness was slightly above average. The most prominent distinguishing characteristics of Segment 3 were its scores on cost and time, so it was named "non-urgent cost seekers" (NCS).

NCS was the most identifiable segment as it had significant positive or negative associations with all descriptors. The most prominent industry of the shippers in this segment was minerals. Refrigerated foods, on the other hand, were negatively associated with this segment, which suggests that refrigerated food shippers are unlikely to fall into this category. Consistent with this, the segment was positively associated with basic materials (52\%) and negatively associated with consumer products $(21 \%)$ while low-value cargoes $(46 \%)$ were the 
leading category and high-value cargoes were the smallest group (8\%). This segment is ranked 6th on cargo sensitiveness and 4th on competition level.

The leading destination of NCS was North America (25\%), whereas Northern Europe was negatively associated with this segment. The great majority of shippers (60\%) ship all their cargoes by seaway. Conversely, the category 'rarely seaway' was negatively associated with this segment, at only 7\%. This segment was also positively associated with 1-9 employee category, which is probably because many block marble shippers are trading companies that sell marble on behalf of the producers. Regarding the most preferred delivery terms, FOB \& FAS were positively related whereas CFR \& CIF were negatively related to NCS.

\section{Segment 4 (Value-added service buyers)}

Segment 4 attached significantly more importance to value-added service (VAS) than other segments, whereas cost was given slightly above average importance and time was slightly below average. Another interesting characteristic of this segment is that it had the lowest mean score on responsiveness. Due to its extreme high score on VAS, this segment was named "VAS buyers" (VASB).

Fashion had the strongest positive association with VASB whereas machine shippers had a negative association. VASB had a very high positive association with high-value cargoes and, conversely, a negative relationship with low-value cargoes. This segment was also negatively associated with the Eastern Mediterranean and North African destinations. Over half of shippers in this segment mostly used seaway transport whereas only $4 \%$ reported using seaways rarely. One of the strongest associations of VASB was monthly container volume, being highly related to shippers that load 100 or more containers per month. Almost half of shippers in this category were in VASB. Conversely, this segment had a negative association with the ' $1-5$ containers per month' category. This segment is ranked 3rd on cargo sensitiveness and 1 st on competition level.

\section{Segment 5 (Relationship seekers)}

Segment 5 had extreme values in more than one selection criterion. First, it had the highest mean score on relations. It also had the highest score on responsiveness, just slightly above Segment 6. Another extreme score for Segment 5 was cost, which had the lowest score, such that it was the lowest of all the factors in Figure 2. Time was also less important for members of this segment, being also less than the overall average. VAS, however, had a higher score than the overall average. This segment stood out for its high value of relational and low value of cost, which suggests that members in this segment may tend to be less pragmatic than those in other segments. Nevertheless, this segment also scored higher on VAS and responsiveness than the overall average across segments. Accordingly, we decided to name it "relationship seekers" (RS). 
Although RS was the least identifiable segment, there were still some important descriptors. Considering industry categories, textiles were positively associated with this segment. The medium-value cargo category, which comprised almost 75\%, was positively related with RS segment. Middle East shipments also had a positive association whereas Northern Europe shipments were negatively related. This is consistent with the pragmatic service buyer segment, which was positively associated with Northern Europe and had very low scores on relations. Finally, the '250 and more employees' category was positively associated with RS. This segment is ranked 5th on cargo sensitiveness and 4th on competition level.

\section{Segment 6 (Time seekers)}

Segment 6 differed from other segments by having the highest score on time. This segment also attached greater importance to responsiveness than the overall average. Another characteristic was that it had the second-lowest score on cost. Regarding time and cost, this segment was the opposite of "non-urgent cost seekers", which scored high on cost and low on time. In contrast, Segment 6 scored high on time and low on cost. Considering these issues, this segment was named "time seekers" (TS).

TS was positively associated with the machine and refrigerated foods industries. Over $50 \%$ of machine shippers and almost 50\% of refrigerated food shippers were clustered in this segment. Minerals, on the other hand, were negatively associated, with only one shipper in TS. Industrial goods were the leading IBC category, comprising almost half of this segment, whereas basic materials had a negative association with this segment. Medium-value products, comprising almost $70 \%$ of the segment, were the major category in terms of cargo value. Low-value products, on the other hand, had a negative relation with this segment. None of the destinations had significant relationships. Regarding the seaway usage rate, this segment was positively related with the 'rarely seaway' category but negatively related with the 'all seaway' category. For the monthly volume of containers, ' $1-5$ shipments per month' was the leading category. Consistent with this, this segment was negatively associated with the ' 100 or more container shipments per month' category. Finally, it was also negatively related with the category for ' 250 or more employees'. This segment is ranked 1 st on cargo sensitiveness and 6th on competition level.

\subsection{Criterion validity of the segmentation analysis}

An important issue of segmentation analysis is to ensure the validity of segments. One of the effective ways of validating the clustering results is criterion validity as suggested by several authors (Hair et al. 2014; Sarstedt and Mooi 2014). Criterion validity is performed by assessing the variables which are not used for clustering but should be related to cluster memberships. Sarstedt and Mooi (2014) state that the criterion validity can be achieved if significant differences are observed between dependent variables across the segments. This paper assesses metric and nominal descriptors, which are not used for clustering, to understand if they show significant differences between the segments in accordance with the theory and practice. 
One of the most prominent criterion validity in our study is achieved with cargo sensitiveness. From the practice and based on the interviews, it is well known that the more sensitive the cargo the more time-sensitive the cargo owner (shipper) is. Thus, a positive correlation is expected between shippers' scores on cargo sensitiveness factor and time factor. The correlation between cargo sensitiveness and time factors is significant and positive with a rate of 0.438. Similarly, we expect cargo sensitiveness to be significantly higher in segments that score higher on time compared to other segments. One-way ANOVA test indicates that cargo sensitiveness shows significant differences among the segments (F=6.682, significance $=0.000$ ). As seen in Table 7, time-sensitive segments (TCS and TS) score significantly higher on cargo sensitiveness. In parallel, refrigerated foods, which are sensitive in nature, are significantly associated with TS segment.

Several nominal descriptors also contribute to proving criterion validity. Cargo value is one of them. It is well known in practice that low-value cargo owners pay more attention to cost rather than time and vice versa. This has been proven in the study of Pedersen and Gray (1998), who has indicated that the time becomes more important than price as the value per ton increases. Considering the cross-tabulation of cargo value and segments, a positive significant association exists between low-value category and NCS segment, which has a very high score on the cost factor. In parallel, a negative significant association exists between low-value category and the time seeker segment. Similarly, high-value cargo category also has a negative association with the NCS segment. All of these are coherent with the study of Pedersen and Gray (1998) as well as the practice.

\section{Discussion}

This study applied market segmentation to container shippers in Turkey by conducting EFA, CFA, cluster analysis, and contingency table analysis. The research revealed a total of six benefit segments of the container shipping market in Turkey. The size of each segment is substantial enough to target through tailored marketing programs. The benefits that these six segments seek are quite distinct as the selection criteria factors are statistically different across the six segments. This means that the segments are differentiable and container lines can apply differentiated marketing offerings for each segment, such as customized communication. It is of critical importance that the segments should also be described by readily available demographic characteristics, which allows segments to be measurable and accessible, as suggested by (Kotler and Armstrong 2011). The segments in our research have statistically significant descriptors, although some segments were more identifiable than others. The industry category of shippers was the only descriptor that was significantly associated with all segments.

The significant associations between the segments and descriptors make sense in practice as well. For instance, NCS has a significant positive association with minerals, basic materials, low-value cargoes, and all seaway transport, which is in accordance with the realities of 
practice. Thus, the association of consumer goods is negative but basic materials is positive. The positive association with 'all seaway usage', the negative association with Northern Europe, and the positive association with North America destinations are also very logical and coherent. It suggests that the shipment destinations of this segment are usually distant overseas. Accordingly, the associations of these distant places are positive (Far East and Asia) whereas nearby locations are negative (Middle East, Eastern Mediterranean).

There are many other statistically significant and practically valid associations in the segments as well. For instance, TS has a strong positive relationship with the machine and refrigerated food industries but a negative one with minerals. Because machines and refrigerated foods are fragile, time is important for these shippers while their value is certainly not low. Rarely seaway users are positively associated with both time-sensitive segments (TCS and TS) whereas it is negatively associated with non-urgent segments. Such associations are coherent with practice, indicating that time-sensitive segments tend to prefer faster modes, such as road. Another interesting association occurs between monthly container volume and segment membership. VASB is the opposite of TCS and TS segments in terms of the importance attached to value-added services and time. Thus, while sending 1-5 containers per month is positively associated with TS and TCS, it is negatively associated with VASB. Conversely, sending 100 or more containers is negatively associated with TCS and TS segments but positively with VASB. This implies that large shippers attach more importance to VAS, including variables such as cargo tracking, storage services, and a wide global network.

The results of this study show both similarities and dissimilarities with the literature. According to Collison (1984), perishable and non-perishable cargoes have different scores on liner shipping service attributes. Our study also confirms that refrigerated and nonrefrigerated cargoes are clustered in different segments. Specifically, refrigerated cargoes are significantly associated with the Time Seeker segment. Lu, Lai and Cheng (2005) reported that export cargo types are statistically different across segments based on the website service attributes of container shipping companies. Our findings are similar to this study since all segments had at least one significant association with industry categories. Our findings are also parallel to Murphy and Daley (1994), who found that sea mode customers and other mode customers have different rankings of selection criteria in terms of reliability and service quality. In our results, customers that always use seaways were significantly associated with NCS whereas customers that rarely use seaways were significantly associated with TCS and TS.

Previous segmentation research in container shipping has focused on single routes (Collison 1984; Matear and Gray 1995; Wen and Lin 2015) whereas our study did not keep route destination constant. The results indicate that some destinations are significantly associated with specific segments. That is, segments are not homogeneous in terms of destinations. To the best of our knowledge, our paper is also the first in the freight transport literature to use relations as a segmentation factor. This study is also the first to use value-added services as a segmentation base in container shipping. Utilization of these two segmentation bases plays an 
important role as container shipping is facing a commoditization issue, so additional services and relations are vital in the market now (Balci, Caliskan, and Yuen 2019; Maloni, Gligor, and Lagoudis 2016).

Another contribution of this study is the determination of industry categories. According to the literature, the standardized industry code tells us little about the benefits sought by industrial customers (Mitchell and Wilson 1998). Our paper acknowledges this issue and proposes using customized industrial divisions that consider the location and business of the segmenting company. This study determined the distribution of each shipper's industry subcategory by considering both the comments of interviewees and shipment statistics. As a result, logical associations and statistical differences were found across sub-groups. This suggests that, for B2B segmentation scholars, a customized industrial breakdown based on regional and industrial characteristics is more effective than the standard industrial classification.

Hair et al. (2014) suggest that standardizing cases in cluster analysis can eliminate respondent bias to provide more accurate segments. In the literature, some studies have applied the standardization of variables in cluster analysis when different scale points are utilized. To the knowledge of the authors, the present study is the first to standardize cases in a B2B study. Compared to non-standardized cluster solutions, standardizing cases reveals a better cluster solution with a more balanced segment membership and more distinctive segments. Scholars interested in segmentation research are advised to implement both case-based standardized and non-standardized cluster solutions and compare the results.

\section{Managerial and Policy Implications}

Our findings also have some implications for container lines. Differentiable segments enable lines to customize their services by considering their strengths and weaknesses as well as customer needs and wants. For instance, in marketing communication with non-urgent cost seekers, it would be pointless if a container line mentioned how transit time is short or how effective its value-added services are. For NCS, the focus should be on price while emphasizing the elements of relationship development. Container lines may have a cost advantage on some routes, so shippers in this segment can especially be targeted for those route(s) on which the line can offer more competitive freights.

Similarly, some container lines present more favorable offers in some destination regions where they possess local advantages. These advantages usually come from services at the destination, such as inland transportation and warehousing. These are the elements of valueadded services. Thus, lines that perform better in these services can target VASB and take actions to serve these customers. For these lines, this segment is quite actionable, which is another effective segmentation criterion (Kotler and Armstrong 2011).

Similar to VAS buyers, pragmatic service buyers can also be targeted with the value-added services. However, to attract customers in this segment, the responsiveness of service should 
also be underlined. In fact, considering the pragmatic behavior of this segment, arising from the very low relations score, the elements of responsiveness and VAS should be demonstrated quantitatively and objectively. For potential customers in this segment, performance reports and customer evaluations (some lines periodically measure customer satisfaction with their services) can be presented quantitatively.

Container lines should emphasize the time factor if they have a direct service, or if the total transit time of their services is short for time seekers and time-sensitive cost seekers. TCS attaches similar importance as NCS to cost, although TCS is concerned about time as well, unlike NCS. It is also not sensitive to relations. Rather, TCS is mostly concerned about the core service. For TCS, lines should promote those routes with shorter transit times and lower freight rates than other lines.

TS, on the other hand, does not attach as much importance to cost as TCS. This suggests that shippers in this segment may ignore cost as long as the line can offer a significant time advantage. Considering the relatively low importance of cost, these customers are willing to pay more for quicker delivery. A deeper analysis could be conducted in this segment to reveal why time is so important. In this way, container lines can explore innovations that satisfy the specific needs of these customers. For example, CMA CGM invented a new container designed to carry lobsters alive. The real need of the shipper may have the lobster fresh, which is why these shippers probably pay more attention to time. Such innovative solutions can enable container lines to compete with air cargo and enjoy premium charges, which is vital in the current market situation. Bearing in mind that the majority of shippers in this segment only rarely prefer sea transport, such innovations can help container lines to compete with air and road.

Relationship seeker, which was the smallest segment, attaches the least importance to cost and time of all segments but has the highest score for relations. Thus, rather than cost and time, container lines in this segment should emphasize the elements of relations. The personnel of the shipping line should focus on building strong relationships with such customers. Given that cost is not considered important, these customers are also unlikely to switch to another line despite receiving a lower freight offer. To accomplish this, a long term relationship should be ensured. Shippers are business customers and the buying process of B2B customers is different to that of consumers. To enhance a relationship with shippers, the perception should be created in the eye of shippers that they actually receive some important benefits with the particular container line they work with. Therefore, container lines should perform well on responsiveness and VAS (this segment scores higher than average) to enhance their relationship with shippers in this segment.

This paper addresses some marketing policy implications in container shipping as well. The container shipping market has become more concentrated due to mergers and acquisitions in recent years. The services of container lines are also becoming more identical following alliance formations. However, customer expectations and priorities are not becoming identical as in the case of supply side. Conversely, customers seek for more customized services. The 
variety of customer priorities has also risen as more kinds of cargoes are carried by containers than ever. Container lines, on the other hand, focus mostly on cost minimization rather than the creation of individual solutions for cargo owners, which makes sense considering the price-based competition and high-cost structure of the market. This situation leads to a gap between the priorities of container lines and cargo owners in the market.

Our research may help close this gap by identifying different customer groups based on their priorities, or needs and wants in other terms, in a cost-efficient way. Our segmentation is costefficient because customer priorities do not have to be explored at the individual level. The segmentation in our research also reflects customer priorities more thoroughly because the segments are created based on customer needs and wants rather than product or company demographics such as perishables, food, or large shippers. Hence, benefit segmentation in our study can help in offering more customized solutions for cargo owners but also staying costefficient. It is for sure that finer segments can be created to reflect customer needs and wants more precisely. However, finer segments also require a sacrifice from cost efficiency, which is a result of the trade-off between cost efficiency and customer priorities.

Container lines face challenging market conditions considering cost minimization and customer expectations. Segmenting customers can allow container lines to gain deeper insights of customer needs and wants, which would enable them to introduce innovations and sustain their market share. Container lines cannot only rely on the growth of the container shipping business. By inventing containers in 1956, McLean grasped the real needs and wants of shippers. Similarly, our segmentation analysis can be a first step for container lines to understand the real needs and wants of customers, and hopefully find the innovations that customers value. Considering the recent challenges that the market faces, such innovations are necessary.

\section{Conclusions}

This paper applied a segmentation analysis on container shippers in Turkey to explore the benefit segments. The segmentation analysis - including EFA, CFA, and cluster analysis ascertains a total of six segments that are differentiable and substantial. A substantial number of statistically significant associations between the segments and descriptors are achieved, which is necessary to identify the benefit segments and ensure criterion validity. The segments can help container lines apply more effective marketing policies by offering customized solutions to shippers.

Market segmentation is one of the most fundamental yet challenging concepts of marketing. Segmentation analysis consists of several important steps, with each requiring great caution. This paper offers comprehensive yet not complete information regarding market segmentation in container shipping. Many more details remain to be explored as well as other important concepts of marketing within the container shipping context. Market segmentation is an ongoing process rather than a fixed phenomenon, especially in dynamic B2B markets like 
container shipping. Therefore, the container shipping market still requires more research in market segmentation with different methodologies and segmentation variables.

\section{Limitations and future research}

This study is also subject to several limitations. The first limitation is that it only focuses on the segmentation of the Aegean Region container shipping market. Although this has some implications for the container shipping market generally, the results derived from our sample can be generalized only for the Aegean Region as the segments identified by this study may not exist in other parts of the world or even Turkey. For instance, it is known in the practice that shippers around Mersin Port region in Turkey attach more importance to personal relations than those in Istanbul. Thus, a future study can be done in another location to compare the results.

The selection criteria in this study included the relationship factor, which is an important issue in many regions of Turkey. However, this may not be as important, let us say, in Northern Europe or North America, so different variables may be needed for segmentation analysis depending on the needs and characteristics of the specific location. Therefore, authors in other regions are advised to conduct preliminary interviews with practitioners to ensure the content validity of the variables specific to that geography.

It was also noticed in the analyses that some of the descriptors could have been more finelytuned. For instance, the range of each cargo value category could have been narrower to provide more effective findings. However, respondents might be unwilling to answer the question in that case. A future study could make the range at least slightly narrower than our categories. In addition, it was not asked if a shipper was the producer of the cargoes or only a trader, which should be asked in a possible future study.

Although customers of container lines include both shippers (exporters and importers) and forwarders, this study only segmented shippers, and only exporters were investigated. Forwarders and importers were excluded for several reasons. First, most of the marketing facilities in the region are directed to exporters rather than importers. Besides, there was no importer association or similar organization from whom we could have received a list of importers to determine the population and select the sample. The container line selection criteria of forwarders and shippers are usually different, so it would not be very logical to segment these two simultaneously in the same analysis using the same variables. Nonetheless, our findings have implications for freight forwarders who are also container shipping service suppliers of exporters. A future study may also segment freight forwarders and importers.

Finally, this study segmented the market generically instead of focusing on a specific purpose, such as innovation or price discrimination. The results would have been much more specific if it had been conducted with the customers of a single container line by considering the segmentation purpose of the company and the resources the company has. Such research 
could be conducted by a future study. Moreover, although a company's buying center usually consists of more than a single person, this study only collected one response from each company. Future studies could include more than one person from each company to discover differences in terms of their needs.

\section{References:}

Bagozzi, R. P. \& Yi, Y. 1988. On the evaluation of structural equation models. Journal of the academy of marketing science, 16(1), 74-94.

Balci, G., \& Cetin, I. B. 2017. Market segmentation in container shipping services: a qualitative study. Management Research Review, 40(10), 1100-1116.

Balci, G., Cetin, I. B., \& Tanyeri, M. 2018. Differentiation of container shipping services in Turkey. Transport Policy, 61. http://doi.org/10.1016/j.tranpol.2017.10.004

Balci, G., Caliskan, A., \& Yuen, K. F. 2019. Relational bonding strategies, customer satisfaction, and loyalty in the container shipping market. International Journal of Physical Distribution \& Logistics Management. Vol. $49 \quad$ No. $\quad 8$, pp. 816838. https://doi.org/10.1108/IJPDLM-02-2019-0051

Brotspies, H., \& Weinstein, A. 2019. Rethinking business segmentation: a conceptual model and strategic insights. Journal of Strategic Marketing, 27:2, 164-176

DOI: $\underline{10.1080 / 0965254 X .2017 .1384750}$

Brown, T.A., 2015. Confirmatory Factor Analysis for Applied Research. Guilford Publications New York

Chao, S. L., \& Chen, B. C. 2015. Effects of switching costs on customer loyalty in the liner shipping industry. Maritime Economics \& Logistics, 17(3), 341-358.

Chen, K. K., Chiu, R.-H., \& Chang, C.-T. 2017. Using beta regression to explore the relationship between service attributes and likelihood of customer retention for the container shipping industry. Transportation Research Part E: Logistics and Transportation Review, $104,1-16$

Chéron, E. J., \& Kleinschmidt, E. J. 1985. A review of industrial market segmentation research and a proposal for an integrated segmentation framework. International Journal of Research in Marketing, 2(2), 101-115. http://doi.org/10.1016/0167-8116(85)90027-8

Collison, F. M. (1984). Market segments for marine liner service. Transportation Journal, $40-54$

Durvasula, S., Lysonski, S., \& Mehta, S. C. 2000. Business-to-business marketing service recovery and customer satisfaction issues with ocean shipping lines. European Journal of Marketing, 34(3/4), 433-452

Fynes, B., de BÚrca, S., \& Voss, C. 2005. Supply chain relationship quality, the competitive environment and performance. International Journal of Production Research, 43(16), 33033320 
Grisé, E., \& El-Geneidy, A. 2018. Where is the happy transit rider? Evaluating satisfaction with regional rail service using a spatial segmentation approach. Transportation Research Part A: Policy and Practice, 114, 84-96.

Hair, J. F., Black, W. C., Babin, B. J., Anderson, R. E., \& Tatham, R. L. 2014. Multivariate data analysis (7th ed.). Essex: Pearson Education Limited

Hu, L. T. \& Bentler, P. M. 1999. Cutoff criteria for fit indexes in covariance structure analysis: Conventional criteria versus new alternatives. Structural equation modeling: $a$ multidisciplinary journal, 6(1), 1-55.

Jadczaková, V. 2013. Responsiveness of culture-based segmentation of organizational buyers. Acta Universitatis Agriculturae et Silviculturae Mendelianae Brunensis, 61(7), 2205-2212.

Jang, H. M., P. B. Marlow, and K. Mitroussi. 2013. "The Effect of Logistics Service Quality on Customer Loyalty through Relationship Quality in the Container Shipping Context." Transportation Journal 52 (4): 493-521.doi:10.5325/transportationj.52.4.0493.

Kannan, V., Bose, S. K., \& Kannan, N. G. (2011). An evaluation of ocean container carrier selection criteria: an Indian shipper's perspective. Management Research Review, 34(7), 754772 .

Ketchen Jr, D. J. \& Shook, C. L. 1996. The application of cluster analysis in strategic management research: an analysis and critique. Strategic management journal, 17(46), 441458

Kline, R.B., 2016 Principles and practice of structural equation modelling. Guilford Publications New York

Kotler, P., \& Armstrong, G. 2011. Principles of marketing (14th ed.). New Jersey: Prentice Hall

Lu, C. S. 2003. The impact of carrier service attributes on shipper-carrier partnering relationships: a shipper's perspective. Transportation Research Part E: Logistics and Transportation Review, 39(5), 399-415.

Lu, C. S., Lai, K. H., \& Cheng, T. C. E. 2005. An evaluation of web site services in liner shipping in Taiwan. Transportation, 32(3), 293-318.

Maloni, M. J., Gligor, D. M., \& Lagoudis, I. N. 2016. Linking ocean container carrier capabilities to shipper-carrier relationships: a case study. Maritime Policy \& Management, 43(8), 959-975.

Malhotra, N. K., \& Birks, D. F. 2007. Marketing Research: An Applied Approach Pearson Education (3rd ed.). London: Prentice Hall Financial Times

Matear, S., \& Gray, R. 1995. Benefit segments in a freight transport market. European Journal of Marketing, 29(12), 43-58.

Mitchell, V.-W., \& Wilson, D. F. 1998. Balancing Theory and Practice: A reappraisal of business to business segmentation. Industrial Marketing Management, 27, 429-445 
Paker, N., \& Vural, C. A. 2016. Customer segmentation for marinas: Evaluating marinas as destinations. Tourism management, 56, 156-171.

Parola, F., Pallis, A. A., \& Song, D. W. 2019. Shipping and Port Marketing: Policy and Strategy, Transport Policy, https://doi.org/10.1016/j.tranpol.2019.03.006

Raman, R., \& Menon, P. 2018. Using social media for innovation-market segmentation of family firms. International Journal of Innovation Science. https://doi.org/10.1108/IJIS-08$\underline{2017-0078}$

Rodrigue, J. P., \& Notteboom, T. 2015. Looking inside the box: Evidence from the containerization of commodities and the cold chain. Maritime Policy \& Management, 42(3), 207-227.

Rencher, A. C. 2002. Methods of multivariate analysis. Second Edition. John Wiley\&Sons Publication Sarstedt and Mooi, 2014

Salavou, H., Baltas, G., \& Lioukas, S. 2004. Organisational innovation in SMEs: the importance of strategic orientation and competitive structure. European Journal of Marketing, 38(9/10), 1091-1112.

Shahrabi, J., Najafabadi, S. M., \& Sahebnasagh, M. 2009. Applying cluster analysis to segment construction steel market. In Industrial Engineering and Engineering Management, 2009. IEEM 2009. IEEE International Conference on (pp. 792-797). IEEE

Tarhini, A., Teo, T., \&Tarhini, T. 2016. A cross-cultural validity of the E-learning Acceptance Measure (ElAM) in Lebanon and England: A confirmatory factor analysis. Education and Information Technologies, 21(5), 1269-1282

Ulaga, W., \& Eggert, A. 2006. Value-based differentiation in business relationships: Gaining and sustaining key supplier status. Journal of marketing, 70(1), 119-136.

Vural, C. A., Göçer, A., \& Halldórsson, Á. 2019. Value co-creation in maritime logistics networks: A service triad perspective. Transport Policy 84, 27-39. https://doi.org/10.1016/j.tranpol.2018.12.017

Wedel, M., \& Kamakura, W. A. 2000. Market segmentation: Conceptual and methodological foundations. (J. Eliashberg, Ed.) International Series in Quantitative Marketing (Second Edi). Massachusetts: Kluwer Academic Publishers

Wen, C.-H., \& Lin, W.-W. 2015. Customer segmentation of freight forwarders and impacts on the competitive positioning of ocean carriers in the Taiwan-southern China trade lane. Maritime Policy \& Management, 1-16

Wong, P. C., Yan, H., \& Bamford, C. 2008. Evaluation of factors for carrier selection in the China Pearl River delta. Maritime Policy \& Management, 35(1), 27-52

Yuen, K. F., \& Thai, V. V. 2015. Service quality and customer satisfaction in liner shipping. International Journal of Quality and Service Sciences, 7(2/3), 170-183. 
